\title{
Gynandroblastoma: a rare case report of ovarian sex cord tumour
}

\author{
S. Tanouti*, I. Elamouri, H. Taheri, H. Saadi, A. Mimouni
}

Department of Obstetrics and Gynecology, Mohammed VI University Hospital Center, Oujda, Morroco

Received: 12 December 2019

Accepted: 06 January 2020

\section{*Correspondence:}

Dr. S. Tanouti,

E-mail: saloua.tanouti@gmail.com

Copyright: (C) the author(s), publisher and licensee Medip Academy. This is an open-access article distributed under the terms of the Creative Commons Attribution Non-Commercial License, which permits unrestricted non-commercial use, distribution, and reproduction in any medium, provided the original work is properly cited.

\begin{abstract}
Gynandroblastoma is an extremely rare ovarian sex cord tumor with malignant potential. An 61-year-old woman, menopausic, consulted for an abdominal pelvic mass. a latero-uterine mass measuring $27.8 \mathrm{~cm}$ in diameter showed a predominantly cystic pattern with a partial solid component. A unilateral adnexectomy was performed. A histopathological examination showed gynandroblastoma composed of juvenile granulosa and Sertoli-Leydig cells, chirurgical treatment was completed by total hysterectomy with right adnexectomy, omentectomy with no proof of malignant cells. We opted for a close observation without adjuvanted chemotherapy. two years after surgery, no signs of recurrence have been noted. The present findings can help clinicians make an accurate preoperative imaging diagnosis of gynandroblastoma with a juvenile granulosa cell component and plan an adequate treatment strategy for this rare, potentially malignant neoplasm.
\end{abstract}

Keywords: Chirurgical treatment, Malignant potential, Rare ovarian tumor, Serum tumor marker

\section{INTRODUCTION}

Gynandroblastoma, a rare tumor of the ovary, is a mixed tumor derived from the sex cords and stroma. Malignant tumor, its malignant potential is however low. ${ }^{1}$ It appears at any age, and its clinical can be either endocrinological, with cycle disorders or hirsutism, either completely dumb except for pelvic mass syndrome. We report the case of a 61-year-old patient consult for abdominal pelvic mass.

\section{CASE REPORT}

A 61-year-old woman, menopausic, with no previous disease history consulted for an abdominal pelvic mass. At this presentation, no virilization symptoms such as hirsutism were evident. Her body mass index was 26.52 . On transvaginal ultrasonography, a latero-uterine mass measuring $27.8 \mathrm{~cm}$ in diameter showed a predominantly cystic pattern with a partial solid component. In the abdominal scan $\mathrm{C}+$, the left adnexal cystic mass was found to have a heterogeneous structure, peripheral solid component and cystic component (Figure 1).
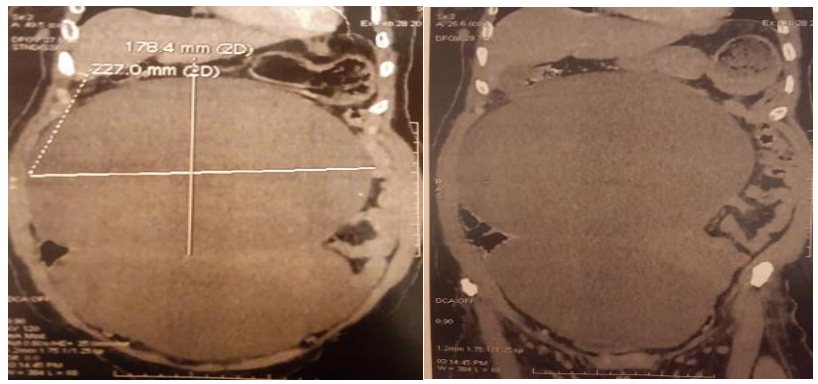

Figure 1: Abdominal scan C+ showed left adnexal cystic mass with heterogeneous structure, peripheral solid component and cystic component.

Serum tumor marker values (alpha-fetoprotein: 2.53 ng/mL, carcinoembryonic antigen: $2.43 \mathrm{ng} / \mathrm{mL}$, CA19-9: $3.19 \mathrm{U} / \mathrm{mL}$, CA125: $30 \mathrm{U} / \mathrm{mL}$ ) were within the normal 
range. Serum human chorionic gonadotropin was not measured since the patient is menopausic.

Since apparent malignant characteristics could not be determined in the left adnexal mass by pre-operative work up, surgical options including adnexectomy by laparotomy.

Laparotomy observation revealed no evidence of an advanced malignant condition such as peritoneal implants in the abdominal cavity. Peritoneal washing cytology showed no malignant cells.

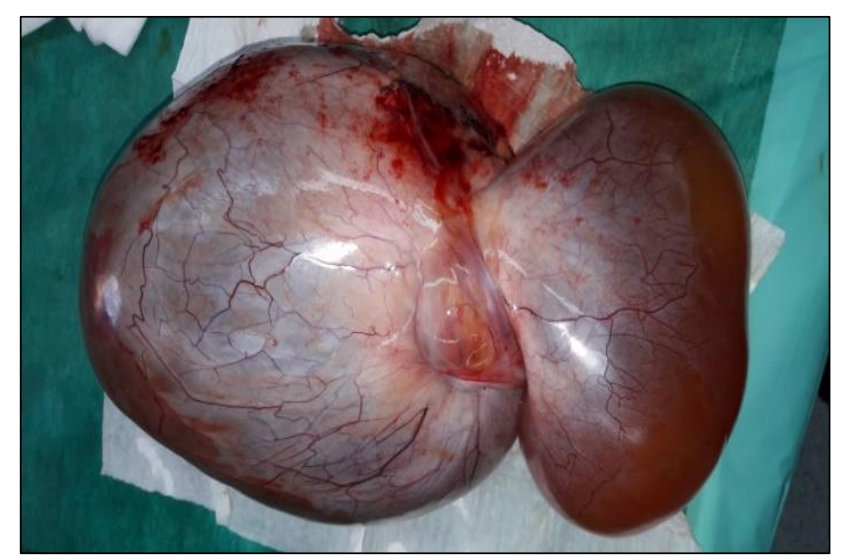

Figure 2: Double component tumor.

The left ovary was enlarged with a mass arriving to the appeindice xyphoid with double cystic and solid component adherent to the abdominal wall (Figure 2).

We realized a left adnexectomy with biopsy of the contralateral ovary, biopsy left and right parieto-colic gutters and epiploic biopsy. The surgical duration was 40 minutes, and the intraoperative blood loss was $100 \mathrm{ml}$ Macroscopically, Piece weighing $4500 \mathrm{~g}$ composed of two cystic masses measuring $25 \times 20 \times 15 \mathrm{~cm}$ and $20 \times$ $13 \times 6$, these two masses are connected by a homogeneous nodular structure with smooth outer surface, firm consistency of pale yellowish color, without territory of necrosis and hemorrhage.

At the opening of two cystic masses, derived from serous fluid, no endo or exo-cystic vegetation.

A histological examination showed a mixed morphology composed of Fusiform cells with hyperchromatic and richly mitotic nuclei in which multiple tubues and tubules are arranged, they are lined with regular cells arranged in 2 to 3 layers (sertoli component) per site we note the presence of a cellular contingent made of small nests of cells of size equal with granular eosinophilic cytoplasm having a central nucleus and nucleated (cells of leydig) the juvenile granulosa cells and the Sertoli-Leydig tumor cells were positive on $\alpha$-inhibin immunohistochemical staining. the diagnosis of gynandroblastoma was retained. Surgical treatment was completed by total hysterectomy, right adnexectomy, omentectomy whose anatomopathological results were in favor of benignity. close observation was decided, clinical observation every 3 months for 2 years, the monitoring of tumor markers every 6 months and radiological monitoring every year from the $2^{\text {nd }}$ to the $5^{\text {th }}$ year. This surveillance was adopted in our patient for 2 years, tumor markers alpha fetoprotein, inhibin A and inhibin B were negative. The radiological control did not find a suspicious image.

\section{DISCUSSION}

The term gynandroblastoma is defined the first time in 1930 by Meyer. It is an ovarian tumor with histology ambiguous association of virilism and endometrial hyperplasia. ${ }^{1}$ In 1958, Morris and Scully re-specify the definition in Whereas the term gynandroblastoma can only be proposed if two distinct cellular female histological contingent and a histological contingent male. This definition is independent of any endocrine symptomatology. ${ }^{2}$

It is taken up by the different pathologists, Novak in 1967, Teillum in 1971 and Serov in 1973. 3,4 At present, it is still widely debated, the problematic being based on the origin of both contingent's female and male. Is it a double cell migration or a secondary differentiation of a single cell strain? ${ }^{4,5}$ The criteria for defining a gynandroblastoma based on the good cellular differentiation of the different cell lines within the same operative part. $^{6}$

Gynandroblastoma publications are rare. The main clinical manifestations of published cases show in order of frequency amenorrhea in 11 cases always associated with virilism; metrorrhagia in two cases; isolated pelvic mass syndrome in one case, as in our observation, finally, for a patient, no clinical sign is present. The mass is palpable in $75 \%$ of cases, it is always unilateral, and its size is very variable, from 5 to $50 \mathrm{~cm}$ in diameter. ${ }^{7,8}$ All ages are affected by this type of tumor, from 10 to 63 years old. ${ }^{8}$

Almost all published tumors were discovered at stage I, the tumor is unilateral, with no neighborhood or lymphatic invasion. The interest of the tumor marker assay is limited because it is not very specific and resides in the follow-up of the patients. If the preoperative rate is high and it collapses after surgery then annual monitoring of the rate is interesting to detect recurrences. The hormonal work-up, estrogen and testosterone, not realized in our observation, show an elevation of the testosterone in $55 \%$ of the cases correlated with the signs of virilization, which our patient didn't had. ${ }^{7}$

The various published cases do not show recurrence during follow-up, which can reach 13 years. It is difficult to draw conclusions in terms of recidivism because each case involves case reports and a prospective series is difficult to envisage. 
A case of postoperative death is reported without further details. $^{3}$

MRI to clarify locoregional and lymphatic extension. Broshears' meta-analysis of 22 cases of gynandroblastoma, with postoperative follow-up limits of six months to 13 years, reports no recurrence. Surgery was most often limited to unilateral adnexectomy in 17 out of 22 cases. $^{9}$

So, must the therapeutic surgical attitude be based on this meta-analysis? Should we be satisfied with unilateral adnexectomy, especially in young women desiring pregnancy with close surveillance? Should we opt for a radical treatment similar to that of a malignant tumor of the ovary containing a total hysterectomy with blateral adnexectomy, associated with a lumbar-aortic iliac lymph node dissection with omentectomy and appendectomy?

One solution might be to create a national or international file of the gynandroblastoma study to define a practical attitude, based on the analysis of a prospective series.

\section{CONCLUSION}

Gynandroblastoma, a rare ovarian tumor, affects all ages, and is most often manifested by cycle disorders associated or not with signs of virilization. Pelvic MRI should be practiced if possible as part of the preoperative assessment. The surgery will consist of a unilateral or bilateral adnexectomy, depending on the age of the patient, or a total hysterectomy with bilateral adnexectomy. Given the slightest doubt of peritoneal dissemination, radical maximalist surgery is essential. The prognosis of these tumors seems to be favourable, however, with the reservations of the meta-analyzes of the literature. The course of action for monitoring this tumor is not well codified. The question of tumor marker assays, imaging, and even second-look surgery remains open. To date, there is no published postoperative recurrence of gynandroblastoma.

Funding: No funding sources Conflict of interest: None declared

Ethical approval: Not required

\section{REFERENCES}

1. Meyer R. The pathology of some special ovarian tumors and their relation to sex characteristics. Am J Obstet Gynecol. 1931;22:697-713.

2. Morris JML, Scully RE. In: Endocrine pathology of the ovary. St-Louis: CV Mosby; 1958:97.

3. Novak ER. Gynandroblastome of the ovary. Review of 8 cases from the ovarian tumor registry. Obstet Gynecol. 1967;30:709-15.

4. Langley FA. In: Fox H, Langley FA, editors. Postgraduate obstetrical and gynaecological pathology. Oxford: Pergamon Press; 1973:225.

5. Luca V, Halalau FL, Oprescu I, Palos N, Florea O. Gynandroblastoma of the ovary. Morphol Embryol Physiol. 1983;29:117-20.

6. Scully RE. Tumors of the ovary and madeveloped gonads. In: Atlas of the tumor pathology, 3rd series, Fasc. 23. Washington, D.C.: Armed Forces Institute Pathol; 1998:219.

7. Martin-Jimenez A, Condom-Munro E, Valls-Porcel M, Giné-Martin L, Del Amo E, Balaguero-Llado L. Gynandroblastome de l'ovaire. Revue de la literature. J Gynecol Obstet Biol Reprod (Paris). 1994;23:391-4.

8. McCluggage WG, Sloan JM, Murnaghan M, With R. Gynandroblastoma of the ovary with juvenile granulosa cell component and heterologous intestinal type glands. Histopathol. 1996;29(3):253-7.

9. Broshears JR, Roth LM. Gynandroblastoma with element resembling juvenile granulosa cell tumor. Int J Gynecol Pathol. 1997;16(4):387-91.

Cite this article as: Tanouti S, Elamouri I, Taheri $\mathrm{H}$, Saadi H, Mimouni A. Gynandroblastoma: a rare case report of ovarian sex cord tumour. Int J Reprod Contracept Obstet Gynecol 2020;9:809-11. 